\title{
Sustainable modeling the life cycle of a real estate development project
}

\author{
Elena Gusakova ${ }^{1, *}$ \\ ${ }^{1}$ Moscow State University of Civil Engineering, 129337, 26, Yaroslavskoye shosse, Moscow, Russia
}

\begin{abstract}
The most well-thought-out strategic planning of real estate development projects is an extremely urgent task. A real estate development project affects the building area throughout the life cycle. The modern concept of the planning horizon of a development project should be based on the analysis of its full life cycle and the consideration of various positive and negative external effects in design decisions. For this purpose, the accumulated representative experience has been studied, the most relevant and demanded areas of forecast analysis have been identified and analyzed, which determine the strategy and specifics of real estate development projects in the early stages. The following specific areas of analysis of the development project were identified: the long-term trend of development of the building $t$ area, scenarios of the project life cycle, the adaptability of project decisions to changes, involvement of interests of groups of the territorial community in the project, the integration of positive effects at the stages of the project life cycle, the multiplier effects of the project. The structure of the positive effects of the forecast analysis of the project is systematized, the accounting of which extends and strengthens the strategic planning of development and becomes the most significant competitive advantage of the project.
\end{abstract}

\section{Introduction}

The Russian real estate market in recent years, having gone through several ups, crises and downturns, has accumulated sufficient experience to summarize conclusions regarding the patterns and features of modeling the life cycle of real estate development projects. In recent decades, the conditions, restrictions, methods and rules of the real estate market have changed so dynamically that a large number of objects that were built only 10-15 years ago, i.e. relatively recently, already morally obsolete from the point of view of the conceptual and design solutions used there. Speaking about current development trends and the state of the real estate market, experts are practically unanimous in the view that the monopolization and disparity of the real estate market is increasing. The deficit period has passed, and the long-term reality is the excess supply of facilities and built space in conditions of low solvent demand. The current state of the industry and the real estate

\footnotetext{
*Corresponding author: GusakovaEA@mgsu.ru
} 
market adversely affects construction production, the capacities of which require load and can currently produce more than necessary. On the other hand, this is a very favorable situation for investors. Changed market conditions turn past approaches into inefficient and become a powerful catalyst for updating approaches and concepts for real estate development [1]. The current stage of the real estate market cycle encourages professional participants to intensively change ideas about a successful development project and develop new concepts [2]. Similar patterns are observed abroad [3]. In the international aspect, we repeat the history of emerging markets - therefore, it is possible and logical to avoid mistakes by analyzing the best Russian and world experience $[4,5,6]$.

\section{Materials and methods}

The implementation of a development project, especially in the case of large and largescale projects, can have a significant impact on the state and directions of territorial and regional development, defining them for many years to come [7, 8]. In most cases, a real estate development project upsets the existing balance of interests in the development area, and therefore it often causes a clear or hidden conflict of interests between project participants and territorial community groups $[9,10]$.

In the construction and development of real estate, the task of forecasting, systematizing, ranking and analyzing the external effects of the project is becoming increasingly important [11-14]. Extensive Russian and foreign development experience, accumulated both on the rise of the market, and in the conditions of overproduction and market stagnation, and in the conditions of its turbulence, reveals a fairly obvious pattern: successful real estate development in any conditions and always is a strategically capacious project. Obviously, the planning of the project strategy includes many complex and highly professional studies, calculations and justifications, requires the processing of large amounts of information [15, 16]. For this purpose, a modern analytical and argumentation toolkit is worked out and can be used in development, based on information modeling and new technologies, including technologies using Big Data, mathematical modeling of demand, the possibilities of analyzing data in dynamics and a large number of iterations [17-21]. The problem is that in practice, these methods of assessment, analysis, justification and argumentation are rarely used. There is no time, resources, sufficient motivation and understanding of the importance of taking into account the long-term negative consequences of the project. As a rule, a project is launched based on emerging opportunities [22, 23, 24].

\section{Results}

The most justified strategic planning of real estate development projects, especially in the context of the growth of their scale and complexity, is an extremely urgent task, because it is not only the basis of professional real estate development, but also a necessary condition for the feasibility and effectiveness of the project, as well as the basis of its competitiveness in the market. Development affects the built-up area and surrounding areas throughout the life cycle, which manifests itself in the form of various positive and negative external effects. As part of pre-project and pre-investment justifications, these effects are analyzed and taken into account with an accessible degree and depth of study.

Provided that the project idea for the development of this particular territory is the most reasonable and best option, the most likely and expected effects are positive. They can be various, including the main effects are analyzed and calculated: 
1) Commercial effects of a development project related to the increase in the value of the surrounding territory and objects due to the increase in market value and profitability of real estate located on the territory;

2) Social effects associated with improving the living environment and livelihoods of people living and working in the territory (including the appearance of new jobs, the development of social facilities, the improvement of the territory, the improvement and development of infrastructure, and many others)

3) project budget effects:

- Related to the growth of taxes and other budget revenues due to construction (including payments for the right to build; taxes on the profits of developers; taxes on the wages of employees, etc.);

- Related to the growth of budget revenues and taxes during the operation of the constructed facility (including taxes on profits of enterprises, taxes on property; land tax, etc.);

- Related to the growth of profitability of surrounding facilities;

- Related to the savings on social benefits in connection with the creation of new jobs and increased employment.

Among the positive external effects of large and wide scale development projects, the multiplier effect of increasing business activity in real estate at all levels of the economy should also be highlighted. The multiplier effect is the result of successful real estate investments that generate activity growth in adjacent territories and related industries: the production of building materials, durable goods increases, demand for housing and communal services increases, etc. [14].

Real estate development projects also generate negative external effects. These are usually temporary effects, such as inconvenience due to construction work. But often the result of the project is not temporary construction inconvenience, but permanent negative external effects. They can be different, delayed in time or long-term. Negative effects arise due to economic, social and environmental miscalculations and "gaps" in the project justifications. Such gaps in the justifications of the development project can lead, for example, to a decrease in the cost of surrounding buildings due to excessive building density or environmental degradation, lower quality and safety of the living environment, etc. $[15,16]$.

Negative effects of the project can appear remotely in time and long-term. A typical and characteristic example of the long-term negative effects of development is the transfer of agricultural land for construction and land development. For comparison, in many countries such projects are considered an encroachment on the country's food sovereignty and are very strictly regulated by law. [14, 19].

\section{Discussion}

The rationale for the decisions of a real estate development project includes the most versatile examinations, calculations and justifications, covers the maximum amount of source data directly or indirectly related to a future project. Conventional research investment plan, project concept, justification of investments, project analysis, feasibility study. A modern approach to the planning horizon of a real estate development project involves an analysis of its full life cycle. Therefore, the pre-investment and pre-project phase and all types of studies performed in the early stages of design are of particular importance in determining the life cycle strategy of a development project. The study of the accumulated representative experience made it possible to identify and systematize the 
most relevant and demanded areas of forecast analysis at the early stages of the project, allowing to determine the strategy and specifics of development.

The first direction of a specific predictive analysis of the development life cycle is the study of the long-term trend of the region's development, the directions and intensity of the changes taking place in the development area, and the correlation of the project idea and project indicators with the research results. Here is the task of integrating knowledge and quality statistics in the areas, prospects and terms of development of the construction territory and surrounding territories. Further, it is important to understand and correctly interpret the information received about what is happening in the economy, how the city and the building area are developing and changing in dynamics. In development, for this purpose, a lot of analytical and applied research is carried out:

- analysis of urban development programs, prospects and dynamics of the city as a whole;

- for medium-sized projects - analysis of the future and infrastructure of the microdistrict, the potential of the district and section, street rating;

- for large and wide scale projects - the study of global analytics and significant factors of influence, the possibilities of integrated development of the territory, the analysis of the cluster division of the city;

- development of a competition map and evaluation of competitive projects;

- analysis of the "ethnosocial" landscape of the territory and differentiation of the income level of residents (for example, by indirect characteristics based on the quarterly structure of the housing stock or the cost of housing);

- - determination of specific locations and spatial "anchors" of long-term economic development, including using geoinformation systems, geomarketing methods;

- determination of the optimal location of the object in terms of profit (for example, based on gravity models).

The methods and models for analyzing the long-term development trend of the building area listed above are an open system - they can be supplemented by other studies depending on the specifics of the real estate development project. The list of necessary studies and the depth of the retrospective and predictive study and assessment of urban planning data also depend on the state of the real estate market. Given the stagnation of the real estate market and high competition, a greater number of iterations are required than on the rise of the market.

The next direction of the forecast analysis of the development project logically follows from the first one and includes the determination of the most probable scenarios of the full life cycle of the project and its harmonization with the development trend of the territory. The purpose of these studies is to predict the life cycle of the project being developed (its goals, content, scope, terms of construction and operation) so that it is most harmoniously implemented in the given construction area. The developer should formulate the widest possible look at the project on the basis of long-term development forecasts. The possible scale, timing, options for the functional content and transformations of the project in the context of crisis, stagnation, market growth are being studied. The most significant success factors of the project at the stages of its life cycle are determined. In studies of this kind, functional economic-mathematical models are used. Then the interests and opportunities of the project participants are studied, a balance of needs and constraints is established. On this basis, form mechanisms and operational models for the implementation of the project in various formats. On the same basis, contractual relations for long-cycle projects are "spliced" when the project is created by the owner of the land plot together with the developer, and then shares or equivalent areas are allocated to the project participants. Justification and harmonization of long scenarios of the life cycle of a development project 
- research is always individual for a particular project, since the real estate market is objectively unsystematic and local.

The third area of long-term forecasting that is significant for successful and highly professional real estate development projects is to involve the interests and needs of the territorial community in the project. Structuring the interests and needs of all social groups living and working in the built-up area, and correlating the project formats, goals, objectives and stages of its life cycle with them, is one of the most relevant and promising areas of research. In real estate development, sufficient representative experience has been accumulated, saying that if the project idea and the very possibility of implementing development is based on the involvement of the interests of all social groups of the territorial community in the project and their consideration in design decisions, the project brings long-term and stable positive effects. This direction of forecasting also covers a wide range of diverse studies, such as:

- Retrospective analysis of the history of the development of the region;

- Study of the demography of the built-up area;

- Analysis of the local target audience: the needs of the territorial community, habits, mentality and preferences of the residents of the region and future owners (including different categories depending on different scenarios of the project life cycle);

- Economic and mathematical modeling of demand for the final product of the project and demand dynamics, etc.

Based on the analysis of social interests, needs and prospects, the location potential of the object is revealed, and fairly clearly defined external criteria for the attractiveness of the development project appear.

Thus, a systematic basis is formed for rapprochement of positions and consolidation of interests of all direct and indirect participants in the project. On this basis, justified and quite specific requirements can be formulated for the project idea, the features of the projected object, for the new functional formats of the object, for its size and class, as well as for its aesthetic, space-planning, architectural and construction, functional and technological design decisions.

A broad look at the real estate development project and the non-standard solution of the problems of consolidating the interests of project participants leads to powerful synergistic effects for the project idea and the territory:

- improving commercial and economic indicators, including the long-term effectiveness of the project life cycle;

- $\quad$ improving the quality of the built-up area as a life support environment and its efficiency in use.

The fourth direction of strategic forecasting of the life cycle of a development project in the early stages of its development is the analysis of the fitness of the facility to the most likely development scenarios, to changing formats and types of its operation and use. In practice, such tasks arise in projects forcibly and in fact more and more often when it is urgent to remove a project from a crisis situation. At the same time, at an early and preinvestment stage, they are set and resolved rarely. This is explained by the high level of uncertainty of the project environment and the fact that economic models and effective commercial concepts, on the basis of which the future of the project is projected, are calculated for a short period of time relative to the life cycle of the development project.

Currently, in the context of accelerated changes and turbulence in the real estate market and the economy as a whole, analysis and consideration in the project of the adaptability of the construction object to development and changes is becoming more and more demanded. The need for certain transformations arises periodically at any building object. It is associated not only with economic, but also with completely predictable engineering and 
technological reasons, such as: modernization and updating of equipment, introduction of innovations, expansion or reduction of production, reconstruction, re-profiling, changing the functional filling of the building's areas, etc. Project participants, designers and economists consider and offer their solutions to the problems of redevelopment and transformation of the project during its life cycle, reflecting different subjective and professional points of view on the construction object. The rapprochement of positions is obviously easier and more effective in the early stages when the most probable and justified needs for transformations can be provided and incorporated into the project by construction, technological and engineering methods and solutions.

Further directions of forecasting the life cycle strategy are based on the results of the justifications already carried out. This is an analysis of the positive effects of different stages and scenarios of the life cycle, the possibilities of combining them. The objective of this study is to ensure the effectiveness, competitiveness and relevance of the project in the long term by predicting scenarios for the full project life cycle and integrating the most likely positive effects. For example, by planning a reasonable duration of operation for the periods of moral aging of the technologies and engineering systems used, as well as the terms of reconstruction, renovation and redevelopment.

In the strategic forecasting of the life cycle of a development project, the multiplicative effects of the project implementation can be considered. The task of development here is not only to conduct a general economic analysis of inter-industry relations in terms of positive effects. The most probable ways of stimulating business, investment and economic activity in the territories and in sectors related to the impact of the commissioned project are discussed. If such opportunities are identified and initiated by the initial project, then the developer can consider the concepts of subsequent projects, optimal projects for the portfolio, and also develop strategic directions for the development company.

The specific directions of the strategic forecast analysis of the real estate development project and the structure of the effects of these studies are systematized in Fig. 1.

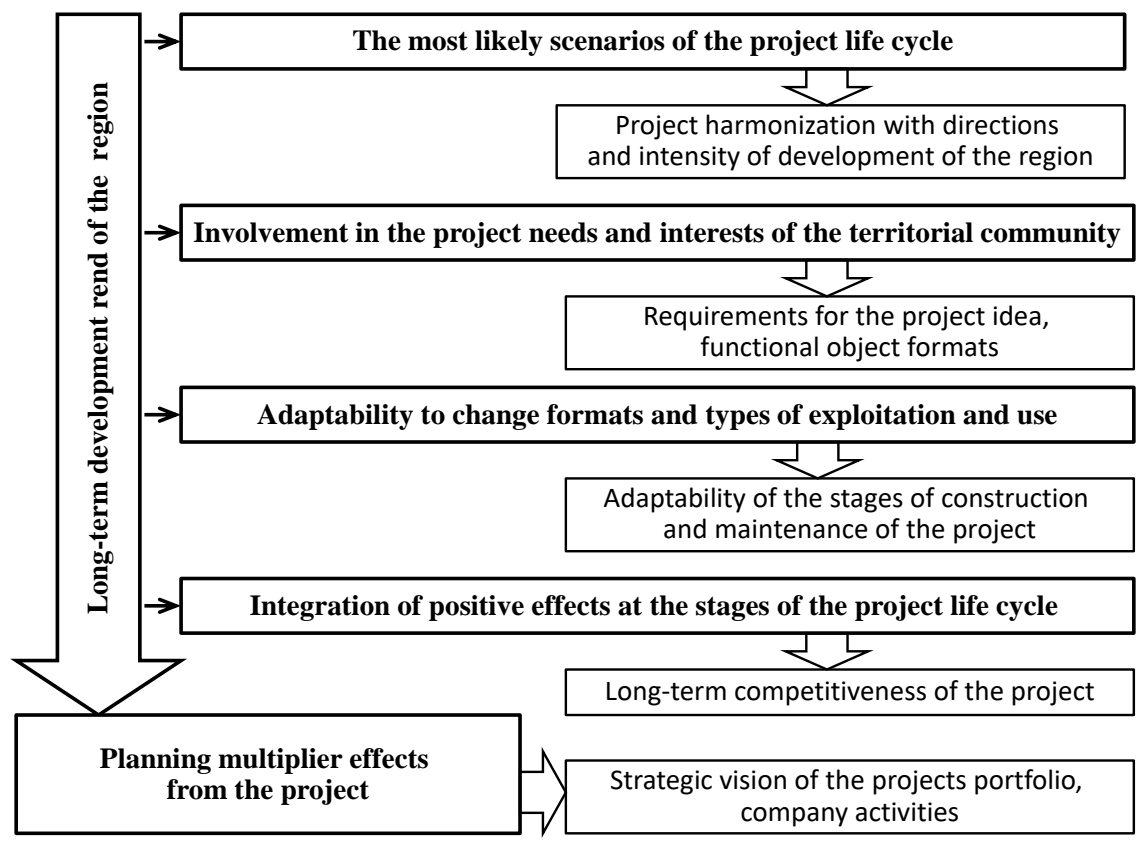

Fig. 1. Specific directions and effects of strategic forecast analysis of a development project 


\section{Conclusions}

Thus, in modern conditions of accelerating changes, the most significant competitive advantages of the project are analysis and consideration of the long-term development trend of the building territory, scenarios of the project life cycle, its adaptability to changes and involvement of the interests of the territorial community in the project. Strategic forecast analysis forms the basis of the project life cycle management from the project idea to its completion, as it provides an opportunity to justify the strategy of the real estate development project at all stages and changes of the building.

The directions of the forecast analysis of the development project, systematized on the basis of accumulated experience, expand opportunities and strengthen strategic planning. This allows you to determine the project development scenario with the most affordable degree of reliability, justify the functional format of the project, the duration and change of stages of its life cycle, organizational and technological, space-planning and structural solutions, optimal projects for the portfolio and much more.

\section{References}

1. A. Volkov, O. Kuzina, Procedia Engineering, 153, 838-843 (2016), doi: 10.1016/j.proeng.2016.08.252

2. K. Figueiredo, A. Hammad, A. Haddad, Reference Module in Materials Science and Materials Engineering (2019), doi.org/10.1016/B978-0-12-803581-8.11360-8

3. P. Evangelista, A. Kiperstok, E. Torres, J. Gonçalves, Construction and Building Materials, 169, 748-761 (2018), doi.org/10.1016/j.conbuildmat.2018.02.045

4. M. Potkany, M. Vetrakova, M. Babiakova, Procedia Economics and Finance, 26, 202208 (2015), doi.org/10.1016/S2212-5671(15)00814-X

5. P. Wilde, Building and Environment, 153, 110-117 (2019), doi.org/10.1016/j.buildenv.2019.02.019

6. A. Marvuglia, U. Leopold, E. Benetto, Renewable and Sustainable Energy Reviews, 74, 316-332 (2017), doi.org/10.1016/j.rser.2017.02.060

7. M. Cellura, F. Guarino, S. Longo, M. Mistretta, Renewable and Sustainable Energy Reviews, 80, 733-742 (2017), doi.org/10.1016/j.rser.2017.05.273

8. S. Geng, Y. Wang, J. Zuo, Z. Zhou, G. Mao, Renewable and Sustainable Energy Reviews, 76, 176-184 (2017), doi.org/10.1016/j.rser.2017.03.068

9. M. Röck, A. Hollberg, G. Habert, A. Passer, Building and Environment, 140, 153-161 (2018), doi.org/10.1016/j.buildenv.2018.05.006

10. J. Brzezicka, R.Wisniewski, M. Figurska, Land Use Policy, 78, 515-531 (2018), doi.org/10.1016/j.landusepol.2018.06.013

11. J. Liu, J. Matthews, C. Sing, J. Smith, Modeling, Automation in Construction, 56, 2635 (2015), doi.org/10.1016/j.autcon.2015.04.008

12. O. Tokede, P. Love, D. Ahiaga-Dagbui, Energy and Buildings, 178, 279-293 (2018), doi.org/10.1016/j.enbuild.2018.08.034

13. M. Renigier-Biłozor, A. Biłozor, R. Wisniewski, Land Use Policy, 61, 511-525 (2017), doi.org/10.1016/j.landusepol.2016.11.040

14. S. Kariyawasam, M. McGovern, C. Wilson, Environmental Impact Assessment Review, 78, 106281 (2019), doi.org/10.1016/j.eiar.2019.106281 
15. O. PrósperoSanchezMarco, A. Oliveira, C. Moraes, International Journal of Project Management, 35 (Issue 8), 1608-1626 (2017) doi.org/10.1016/j.ijproman.2017.09.007

16. W. Tang, Y. Wang, Habitat International, 63, 1-10 (2017), doi.org/10.1016/j.habitatint.2017.03.006

17. G. Pérez, L. Cabeza, Encyclopedia of Sustainable Technologies. 275-290 (2017) doi.org/10.1016/B978-0-12-409548-9.10194-0

18. N. Olsson, A. Sorensen, G. Leikvam, Procedia Economics and Finance, 21, 524-531 (2015), doi.org/10.1016/S2212-5671(15)00208-7

19. G. Squires, E. Heurkens, Land Use Policy, 50, 573-581 (2016), doi.org/10.1016/j.landusepol.2015.10.005

20. A. Volkov, E. Gusakova, A. Ovchinnikov, E3S Web of Conference, 97, 01002 (2019), https://doi.org/10.1051/e3sconf/20199701002

21. E. Mostavi, S. Asadi, D. Boussaa, Energy, 121, 606-615 (2017), doi.org/10.1016/j.energy.2017.01.049

22. A. Volkov, L. Shilova, Procedia Engineering, 153, 844 - 849 (2016), doi: 10.1016/j.proeng.2016.08.253

23. Z. Lancaster, R. Binder, K. Matsui, P. Yang, Energy Procedia, 158, 4210-4217 (2019), doi.org/10.1016/j.egypro.2019.01.807

24. L. Ma, Y. Le, Q. He, J. Zhang, Procedia - Social and Behavioral Sciences, 74, 31-40 (2013), doi: 10.1016/j.sbspro.2013.03.043 